\title{
Pulmonary herpes simplex in burns patients
}

\author{
R.J. Byers*, P.S. Hasleton+, A. Quigley+, C. Dennett**, \\ P.E. Klapper**, G.M. Cleator**, E.B. Faragher ${ }^{++}$
}

Pulmonary herpes simplex in burns patients. R.J. Byers, P.S. Hasleton, A. Quigley, C. Dennett, P.E. Klapper, G.M. Cleator, E.B. Faragher. CERS Journals Ltd 1996.

ABSTRACT: In this study we aimed to determine the incidence of herpes simplex virus (HSV) in the lungs of burns patients, and its association with the presence of adult respiratory distress syndrome (ARDS) and pneumonia.

Haematoxylin and eosin (H\&E), and immunohistochemical (IHC) staining for HSV was performed on lung tissue from 54 patients who had died following burn injury and from nine control cases. Polymerase chain reaction (PCR) for HSV deoxyribonucleic acid (DNA) was performed on a subset both of burns cases and controls.

No viral inclusions were detected in $\mathrm{H} \& \mathrm{E}$ sections, but $50 \%$ of the burns cases were positive for HSV by IHC staining; no control cases were positive. Nuclear and cytoplasmic immunopositivity for HSV was seen in macrophages and epithelial lining cells. HSV was strongly associated with ARDS $(p=0.007)$, but not with pneumonia $(p=0.577)$. The relative risk of HSV infection was higher for cases with ARDS (2.21) than for those with pneumonia (1.26). PCR for HSV DNA was positive in three out of five burns cases, and in one out of five control cases.

Immunohistochemical staining is more sensitive for the detection of herpes simplex virus than haematoxylin and eosin staining for detection of viral inclusions. Burns cases have a high incidence of pulmonary herpes simplex virus infection. Polymerase chain reaction results may not be fully representative due to problems of tissue necrosis postmortem. Pulmonary herpes simplex virus is strongly associated with adult respiratory distress syndrome and the two may be causally linked. Early detection and treatment of pulmonary herpes simplex virus in burns patients may reduce pulmonary complications and mortality.

Eur Respir J., 1996, 9, 2313-2317.

Patients with severe cutaneous burns have a high mortality, largely due to respiratory complications [1], which are more severe in those with associated thermal lung injury. Pulmonary infection $[2,3]$ and the adult respiratory distress syndrome (ARDS) $[4,5]$ are common and difficult conditions to treat in these patients. Both conditions are associated with increased morbidity and mortality.

Whilst viral infections have been considered relatively unimportant in burns patients [6], several reports have suggested that herpes simplex virus (HSV) may be detected in the lower respiratory tract of a large proportion of patients with burns or ARDS [7, 8]. However, identification of the presence of HSV in these patients has relied on the detection of viral intranuclear inclusions in haematoxylin and eosin (H\&E) stained sections. This method may have a low sensitivity, since the lungs of burns patients are often inflamed and may be necrotic as a result of bacterial pneumonia and/or ARDS. These conditions may mask viral inclusions.

To confirm that HSV infection may be found in the lungs of patients with thermal injury, its presence was investigated using conventional $\mathrm{H} \& \mathrm{E}$ and immunohistochemical staining, in situ hybridization and polymerase chain reaction (PCR) on paraffin wax-embedded formalin-fixed tissues from fatal cases.
Divisions of *Pathology and **Virology, Dept of Pathological Sciences, University of Manchester, Clinical Sciences Building, Manchester Royal Infirmary, Manchester, UK. +Dept of Histopathology, Wythenshawe Hospital, Manchester, UK. ${ }^{++}$Dept of Medical Statistics, Withington University Hospital of South Manchester, Manchester, UK.

Correspondence: R.J. Byers

Dept of Pathological Sciences Stopford Building

University of Manchester

Oxford Road

Manchester M13 9PT

UK

Keywords: Burns

herpes simplex

lungs

Received: November 101995

Accepted after revision July 171996

\section{Methods}

Samples of lung tissue, embedded in paraffin wax, were selected from archival files of autopsy cases. Material was available from 54 burns patients. Review of the clinical notes revealed no suspicion of pulmonary HSV infection at the time of death. The control group comprised nine patients who died immediately following road traffic accidents. The number of lung blocks examined in each case varied from one to 14 , with a mean of three.

Tissue was fixed for $24-48 \mathrm{~h}$ in buffered $10 \%$ formol saline and routinely processed to paraffin wax blocks. Sections from these blocks were cut at $4 \mu \mathrm{m}$ and dried onto slides at $35^{\circ} \mathrm{C}$ overnight. $\mathrm{H} \& \mathrm{E}$ stained sections were examined to determine the pathology of the pulmonary disease and were screened at high magnification $(\times 400)$ for viral inclusion bodies.

\section{Immunohistochemistry}

Further sections were stained with a polyclonal rabbit antibody to HSV type 1 (HSV-1) (B0114; Dako, UK) using an indirect avidin-biotin complex immunoperoxidase method, with trypsin pretreatment and dye 
precipitation with diaminobenzidene. This antibody is prepared from HSV-1 infected rabbit cornea cells, but acts against both type-specific and type-common antigens (i.e. types 1 and 2). Differences in frequency of HSV positivity between groups were tested by the $\chi^{2}$ test of association, using 95\% confidence limits to indicate the precision of approximation of the study estimates to population values.

\section{In situ hybridization}

Blocks from five burns cases positive for HSV antigen by immunohistochemistry, and from five control cases were selected for further study by in situ hybridization and PCR. In situ hybridization [9] was performed for the detection of HSV nucleic acid using an 800 base pair (bp) biotinylated probe pA29 [10], homologous with a region of the HSV thymidine kinase (TK) gene.

Paraffin sections were dewaxed in citroclear, rehydrated through graded alcohols and pretreated with 1.2 $\mu \mathrm{g} \cdot \mathrm{mL}^{-1}$ pepsin in $0.01 \mathrm{M} \mathrm{HCl}$ at $37^{\circ} \mathrm{C}$ for $1 \mathrm{~h}$. Cellular and probe DNA were denatured simultaneously at $80^{\circ} \mathrm{C}$ for $10 \mathrm{~min}$, and hybridized overnight at $42^{\circ} \mathrm{C}$. The probe was delivered in hybridization buffer $(2 \times$ sodium chloride/trisodium citrate (SSC), $50 \%$ formamide, $5 \%$ dextran sulphate, $0.1 \mathrm{mM}$ ethylenediamine tetra-acetic acid (EDTA), $0.5 \mathrm{mM}$ Tris-HCl (pH 7.3), and $20 \mathrm{ng} \cdot \mu \mathrm{L}^{-1}$ herring sperm DNA). Sections were washed twice for 20 min at room temperature in $2 \times \mathrm{SSC}$, and twice for 20 $\min$ at $56^{\circ} \mathrm{C}$ in $0.2 \times \mathrm{SSC}$ posthybridization. Hybridized probe was detected via a streptavidin/alkaline phosphatase conjugate and dye precipitation with nitro blue tetrazolium and bromo-chloro-indolyl phosphate [11]. Sections were independently examined by three of the authors (CD, PEK and GMC).

\section{Polymerase chain reaction}

Paraffin sections were dewaxed and DNA extracted by digestion with proteinase $\mathrm{K}$ and sodium dodecyl sulphate (SDS), followed by phenol/chloroform extraction and ethanol precipitation [9]. Precipitated DNA was resuspended in $50 \mu \mathrm{L}$ of sterile distilled water and $5 \mu \mathrm{L}$ of this was used in the PCR. The PCR reaction mixture consisted of $100 \mathrm{nM}$ of each oligonucleotide primer (oligonucleotide primers which amplify a $351 \mathrm{bp}$ fragment within the HSV-1 TK gene [12]), $200 \mu \mathrm{mol}$ deoxynucleotide triphosphates (dNTPs), $0.05 \mathrm{M} \mathrm{KCl,} 2$ $\mathrm{mM} \mathrm{MgCl}, 0.02 \%$ bovine serum albumin (BSA) and 2.5 units of $\mathrm{Taq}$ polymerase in $0.01 \mathrm{M}$ Tris- $\mathrm{HCl}$ at $\mathrm{pH}$ 8.3. The reaction mixtures were subjected to 50 cycles at $94^{\circ} \mathrm{C}$ for $2 \mathrm{~min}, 50^{\circ} \mathrm{C}$ for $1.5 \mathrm{~min}$, and $70^{\circ} \mathrm{C}$ for 2 min. Reaction products were analysed by agarose gel electrophoresis and Southern blotting, using a $128 \mathrm{bp}$ probe for a region within the $351 \mathrm{bp}$ amplicon [12].

\section{Results}

The burns patients (23 females and 31 males) were aged 18-90 yrs, mean 56 yrs. The control subjects (6 males and 3 females) were aged 22-83 yrs, mean 46 yrs. Length of survival after burn injury was documented in 44 cases and varied from less than $1 \mathrm{~h}$ to 60 days, with a mean of 9 days. The percentage burn, also documented in 44 cases, ranged 1-90\%, with a mean of $36 \%$. Cases in which the percentage burn was low were elderly ( $>80 \mathrm{yrs}$ ) or were associated with facial involvement. In addition, one patient aspirated gastric contents following a $5 \%$ facial burn.

Mean duration of survival and mean percentage burn were similar both in HSV positive and negative cases (7.9 vs 10.8 days, and 35.4 and $39.2 \%$ respectively; neither difference being statistically significant).

Bacterial pneumonia was identified histologically on the basis of neutrophil infiltration in 21 of the 54 cases, whilst ARDS was diagnosed on the basis of hyaline membrane formation in 16 cases; evidence of both was present in 11 cases. No significant pulmonary pathology was identified in 28 cases. Many of these patients were elderly and died either of intercurrent disease exacerbated by burn injury, such as ischaemic heart disease, of other complications of burn injury, such as septicaemia, or of unrelated disease during hospitalization, such as pulmonary embolus. The range of percentage burn was similar in those with and without pulmonary involvement (2-80\% and $1-90 \%$, respectively), though the mean percentage burn in those with no pulmonary disease was significantly lower than in those with disease (28 and 44\%, respectively; $\mathrm{p}<0.05$ ).

Typical herpetic viral inclusions were not detected in H\&E sections from either the burns cases or the control group. However, immunopositivity for HSV was found in 27 of the 54 burns cases (50\%). Staining was focal and mainly cytoplasmic, though nuclear staining was also present. Staining was observed in intraalveolar and interstitial macrophages, and in epithelial lining cells (fig. 1). None of the nine controls were positive; this difference was significant (Fisher exact test $\mathrm{p}=0.008$ ). The control group was small due to the difficulty in finding suitable subjects, but the results were nonetheless statistically significant.

Immunohistochemical positivity was strongly associated with ARDS but not with pneumonia. Thirteen out of the $16(81 \%)$ ARDS cases were positive, compared with 14 of the $38(37 \%)$ non-ARDS cases $\left(\chi^{2}(1)=7.194 ; p=\right.$ 0.007) (table 1). The relative risk of HSV positivity in those with ARDS compared with those without ARDS

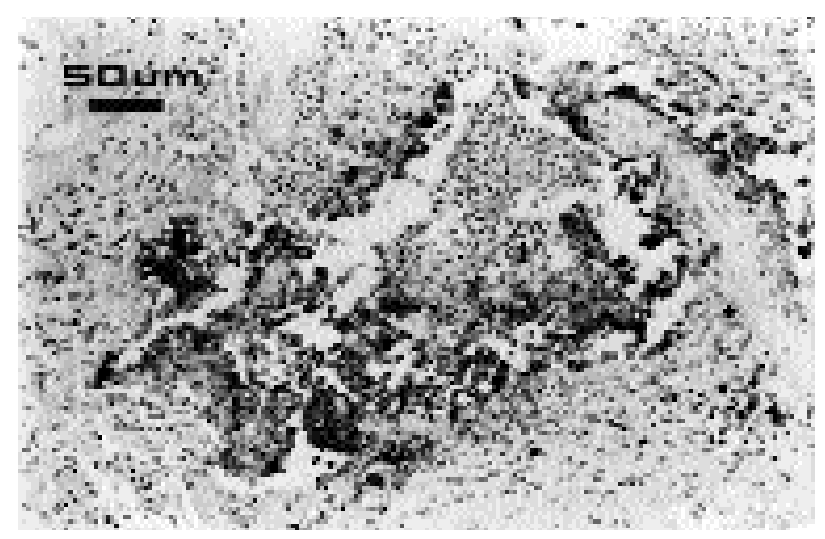

Fig. 1. - Immunopositivity for herpes simplex virus in epithelial lining cells and interstitial macrophages. 
Table 1. - Association of herpes simplex with ARDS

\begin{tabular}{|c|c|}
\hline \multicolumn{2}{|c|}{$\begin{array}{c}\text { Burns cases } \\
\quad(\mathrm{n}=54)\end{array}$} \\
\hline Without ARDS & With ARDS \\
\hline $\begin{array}{l}38(10 ; 50-82) \\
\text { Positive }\end{array}$ & $\begin{array}{l}\text { Positive } \\
\text { Po }\end{array}$ \\
\hline $14(37 ; 22-54)$ & $13(81 ; 54-96)$ \\
\hline Negative & Negative \\
\hline $24(63 ; 46-78)$ & $3(19 ; 4-46)$ \\
\hline
\end{tabular}

Values are presented as absolute number, and percentage and 95\% confidence limit in parenthesis. ARDS: adult respiratory distress syndrome.

Table 2. - Association of herpes simplex with pneumonia

\begin{tabular}{lll}
\hline & $\begin{array}{c}\text { Burns cases } \\
(\mathrm{n}=54)\end{array}$ & \\
\hline Without pneumonia & & With pneumonia \\
$33(61 ; 47-74)$ & & $21(40 ; 26-53)$ \\
Positive & Positive \\
$15(46 ; 28-64)$ & $12(57 ; 34-78)$ \\
Negative & Negative \\
$18(55 ; 36-72)$ & $9(43 ; 22-66)$ \\
\hline
\end{tabular}

Values are presented as absolute number, and percentage and $95 \%$ confidence limit in parenthesis.

was 2.21 (95\% confidence limits (95\% CL) 1.37-3.56). Conversely, 12 out of the $21(57 \%)$ cases with pneumonia were positive, compared with 15 of the $33(46 \%)$ cases without pneumonia $\left(\chi^{2}(1)=0.312 ; \mathrm{p}=0.577\right)($ table 2$)$. The relative risk of HSV positivity in those with pneumonia compared with those without pneumonia was 1.26 (95\% CL 0.74-2.13). Eight of the 11 (73\%) cases with both pneumonia and ARDS were positive. HSV was detected in 9 of the $28(32 \%)$ cases without evidence of pulmonary disease.

HSV was detected by in situ hybridization in one of five blocks selected from the burns patients, but in none of the five control blocks. HSV was detected by PCR in three of the blocks from burns cases, and in one of the controls (table 3). PCR amplification of the beta-globin gene showed efficient extraction of DNA in each case.

Table 3. - Results of in situ hybridization (ISH), polymerase chain reaction (PCR) and immunohistochemical staining (IHC) in selected blocks from burns and control patients

\begin{tabular}{lccc}
\hline & ISH & PCR & IHC \\
\hline Burns group & & & \\
1 & + & - & + \\
2 & - & - & + \\
3 & - & + & + \\
4 & - & + & + \\
5 & - & - & + \\
Control group & & + & - \\
1 & - & - & - \\
2 & - & - & - \\
3 & - & - & - \\
4 & - & - & - \\
5 & - & & \\
\hline
\end{tabular}

+: positive; -: negative.
Evidence of acute damage in the large and small airways, demonstrated by either acute inflammation or epithelial sloughing, was present in 19 cases and absent in 35. Further analysis of these two groups showed no significant differences in the incidence of either ARDS or bronchopneumonia between the two groups; ARDS alone was present in one case with airways damage and four without, bronchopneumonia in four with and six without, both in seven with and four without, and neither in seven with and 21 without. Similarly, HSV was detected in nine cases with damage and 10 without, and was absent in 17 with and 18 without.

\section{Discussion}

No herpetic inclusions were seen in $\mathrm{H} \& \mathrm{E}$ sections, but using IHC staining $50 \%$ of the burns cases were positive for HSV, whilst none of the control cases were positive. Ideally, culture should be used to confirm the presence of HSV but, in the absence of clinical suspicion, this was not carried out at the time of autopsy and cannot be done using archival material. The presence of HSV was strongly associated with ARDS ( $\mathrm{p}=0.007)$ but not with pneumonia $(\mathrm{p}=0.577)$, and the relative risk of HSV infection was higher for cases with ARDS (2.21) than for those with pneumonia (1.26). The incidence of HSV in those with both ARDS and bronchopneumonia $(73 \%)$ is closer to that of those with ARDS than with bronchopneumonia as a group, supporting an association with ARDS rather than with bronchopneumonia.

HSV infection of the lower respiratory tract is considered rare [13]. It has been described in immunosuppressed patients [14-21], in neonates who contract it in the birth canal [22], and in four autopsy series [2326]. In those series which examined all autopsies in a given hospital, the incidence of pulmonary HSV ranged $0.002-0.01 \%[23,24]$, but in a study concentrating on burns patients alone the incidence was $10 \%$ [26].

NASH and Foley [26] identified 15 patients with herpetic involvement of the lower respiratory tract, 14 of whom had burn injuries. Infection was located in the trachea and bronchi in 37 of the cases pooled from four autopsy series [23-26], and in the parenchyma of 13 patients. TUXEN et al. [8] reported the presence of HSV, detected by identification of inclusion bodies in tracheobronchial secretions, in 14 of $46(30 \%)$ patients with ARDS, and suggested that the true incidence was probably higher. Immunofluorescence confirmed its presence in eight of a subgroup of 10 cases [8]. In these cases, ARDS was due to nonthermal causes and the increased incidence of HSV in the present study may be due to sloughing of the bronchial epithelium by inhaled superheated smoke or flames, facilitating infection in burns patients.

We found a high incidence $(50 \%)$ of pulmonary HSV immunopositivity confirming the high incidence of pulmonary HSV suggested by NASH [24], and identified by TuXEN et al. [8]. The incidence in this study exceeds that found by TUXEN et al. [8] (30\%) who detected HSV by cytopathic features in tracheobronchial secretions, whilst in the present study the lung parenchyma was examined using IHC staining; both factors should improve the detection rate. Herpetic infection results 
in characteristic intranuclear inclusions in $\mathrm{H} \& \mathrm{E}$ stained sections [13]. Despite high power $(\times 400)$ screening, such inclusions could not be detected in the burns cases, suggesting greater sensitivity of IHC staining. Pneumonia and ARDS leads to inflammation and necrosis, resulting in pyknotic and apoptotic nuclei, which mask intranuclear inclusions. The cytopathic changes seen in lavage fluid or in tracheobronchial secretions are different to those in tissue sections and are less prone to the problems of identification posed by accompanying inflammation and necrosis, which are in addition less marked in these types of sample compared with tissue sections. This explains the apparent discrepancy between identification of HSV by TuXEN et al. [8] and the lack of convincing inclusions in the present study. Unfortunately, the cases examined died before the advent of routine bronchoalveolar lavage, which would have been a useful adjunct in the identification of HSV.

The polyclonal antibody used in this study stains nuclear and cytoplasmic viral proteins produced during viral replication and serves to overcome the problems of interpretation discussed above. IHC staining was detected in the nucleus and cytoplasm of macrophages and epithelial cells. In positive cases, staining, though focal, was present in several places in each block, suggesting widespread infection.

Failure to detect HSV DNA using PCR in two of the five cases positive by IHC staining, and in four of the five using in situ hybridization might be explained by postmortem digestion of the DNA by endogenous nucleases. Because of severe lung injury, the tissue is partially necrotic. Nicoll et al. [27] found a similar discrepancy between the results of immunohistochemistry and PCR in postmortem tissue. They attributed the discrepancy to postmortem necrosis, with release of nucleases, which would digest nucleic acid but leave viral proteins intact. Furthermore, since the immunopositivity was focal, a sampling error may have been introduced by further sectioning of the blocks examined; HSVspecific antigens could not be detected by IHC staining in sections directly adjacent to those used for in situ hybridization. The focal nature of the infection may also have compromised detection by in situ hybridization.

Pulmonary HSV was strongly associated with the presence of ARDS but not with pneumonia, and the relative risk of infection was higher with ARDS than with pneumonia (2.21 compared with 1.26). The histological appearance of acute herpetic pneumonitis is similar to that of the initial exudative phase of ARDS [13]. Consequently, in some cases, the histological features thought to have been due to ARDS may have been due to herpetic pneumonitis. Indeed, ODA et al. [28] recently reported an increase in the extent of HSV infection in the lungs of patients with secondary diffuse interstitial pneumonia, which may represent a healing phase of ARDS. Recognition of herpetic intranuclear inclusions may be difficult in lungs which are inflamed and necrotic. Furthermore, HSV may be the initiating factor in some cases of ARDS, though without longitudinal studies it is impossible to determine whether ARDS or HSV infection occurs first. The lower incidence of HSV $(32 \%)$ in those without evidence of pulmonary disease, and in whom the mean percentage burn was also lower than in those with either ARDS or bronchopneumonia, suggests that the presence of HSV is a function of the severity of the initial systemic stress and that overt pulmonary disease follows on from this. In addition, whilst this study looked only at burns cases, ARDS and HSV may be more generally linked, as suggested by NASH and FOLEY [26], and this wider area needs further study. However, in our hospital, herpetic infection has been seen in only one case of a total of 92 lung transplants, despite these cases being at risk due to problems of vascular damage, bacterial infection and rejection.

Infection might be due to reactivation of latent HSV [8] in the vagal ganglia [28, 29] or oropharynx, as a result of the stress of burn injury, or due to primary infection. The suggestion made above, that the presence of HSV is dependent on the severity of the initial stress of a burn injury, would be consistent with such a mechanism. In addition, the lack of significant differences in the incidence of HSV or of either ARDS or bronchopneumonia in those with or without airways damage supports the implication that the presence of HSV is due to stress related reactivation, which would lead to alveolar rather than airways involvement. Similarly, the lower incidence in those without pulmonary disease may reflect subclinical activation, which has not been aggressive enough to precipitate morphological change.

In the present study, no association was found between either duration of survival after burn or percentage burn. TUXEN et al. [8] found that the presence of HSV in ARDS was associated with higher mortality and morbidity. However, as all of the patients in the present study died following their burn they are not directly comparable.

Though the control group is small, we have demonstrated a strong association between herpes simplex virus and adult respiratory distress syndrome in burns patients. Further study, preferably including bronchoalveolar lavage, is indicated to confirm this result and to establish if this association is causal. This is important, since safe and effective antiviral therapy (acyclovir) is available for herpes simplex virus and may diminish respiratory complications in patients with burn injuries. Infection may be detected by examination of bronchoalveolar lavage fluid obtained at endoscopy, which is safe in patients with adult respiratory distress syndrome [30] and effectively samples the lower respiratory tract [31].

Acknowledgements: The authors are grateful to R.E. Bonshek, Dept of Pathological Sciences, University of Manchester, for help with interpretation of results, to the technical staff of the histopathology laboratory, Wythenshawe Hospital for preparation of sections and to P. Tarpey for photographic work.

\section{References}

1. Haponik EF, Munster AM. Diagnosis, impact, and classification of inhalational injury. In: Haponik EF, Munster AM, eds. Respiratory injury: Smoke Inhalation and Burns. New York, McGraw-Hill, 1990; pp. 17-45.

2. Luterman A, Dasco CC, Curreri WP. Infections in burn patients. Am J Med 1986; 81 (Suppl. 1A): 45-52.

3. Bruck HM, Nash G, Stein JM, et al. Studies on the occurrence and significance of yeasts and fungi in the burn wound. Ann Surg 1972; 176: 108-110. 
4. Hasleton PS, McWilliam L, Haboubi NY. The lung parenchyma in burns. Histopathology 1983; 7: 333-347.

5. Haponik EF, Crapo RO, Traber DL, et al. Smoke inhalation. Am Rev Respir Dis 1988; 138: 1060-1063.

6. Graham BS, Snell JD. Herpes simplex virus infection of the adult lower respiratory tract. Medicine 1983; 62: 384-393.

7. Foley FD, Greenwald KA, Nash G, Pruitt BA. Herpes virus infection in burned patients. N Engl J Med 1970; 272: $26-29$

8. Tuxen DV, Cade JF, McDonald MI, et al. Herpes simplex virus from the lower respiratory tract in adult respiratory distress syndrome. Am Rev Respir Dis 1982; 126: 416-419.

9. Cleator GM, Klapper PE, Dennett C, et al. Corneal donor infection by herpes simplex virus: herpes simplex virus in donor corneas. Cornea 1994; 13: 294 304.

10. Efstathiou S, Minson AC, Field HJ, Anderson JR, Wild P. Detection of herpes simplex virus-specific DNA sequences in latently infected mice and in humans. $J$ Virol 1986; 7: 446-455.

11. Leary JJ, Brigati DJ, Ward DC. Rapid and sensitive colorimetric method for visualising biotin-labeled DNA probes hybridized to DNA or RNA immobilized on nitrocellulose: Bio-blots. Proc Natl Acad Sci USA 1983; 50: 4045-4049.

12. Klapper PE, Cleator GM, Dennett C, Lewis AG. Diagnosis of herpes encephalitis via Southern blotting of cerebrospinal fluid DNA amplified by polymerase chain reaction. J Med Virol 1990; 32: 261-264.

13. Katzenstein A-L. Unusual pneumonias. In: Katzenstein A-L, Askin FB, eds. Non-neoplastic Lung Disease. Philadelphia, Saunders, 1982; pp. 209-212.

14. Cheever A, Valsamis M, Rabson A. Necrotizing toxoplasmic encephalitis and herpetic pneumonia complicating treated Hodgkin's disease. N Engl J Med 1965; 272: 26-29.

15. Douglas R, Anderson S, Weg J, et al. Herpes simplex virus pneumonia: occurrence in an allotransplanted lung. J Am Med Assoc 1969; 210: 902-904.

16. Case records of the Massachusetts General Hospital. $N$ Eng J Med 1973; 288: 780-787.

17. Case records of the Massachusetts General Hospital. $N$ Eng J Med 1973; 288: 1173-1180.
18. Jordan SW, McLaren LC, Crosby JH. Herpetic tracheobronchitis. Arch Intern Med 1975; 135: 784-788.

19. Morgan HR, Finland M. Isolation of herpes virus from a case of atypical pneumonia and erythema multiforme exudativum: with studies of four additional cases. Am J Med Sci 1965; 217: 92-95.

20. Caldwell JE, Porter DD. Herpetic pneumonia in alcoholic hepatitis. J Am Med Assoc 1971; 217: 1703.

21. Case records of the Massachusetts General Hospital. $N$ Eng J Med 1973; 289: 91-99.

22. Greene GR, King D, Romansky SG, Marble RD. Primary herpes simplex pneumonia in a neonate. Am J Dis Child 1983; 137: 464-465.

23. Herout V, Vortel V, Vondrackova A. Herpes simplex involvement of the lower respiratory tract. Am J Clin Pathol 1966; 46: 411-419.

24. Nash G. Necrotising tracheobronchitis and bronchopneumonia consistent with herpetic infection. Hum Pathol 1972; 3: 283-291.

25. Buss DH, Scharyj MS. Herpes virus infection of the esophagus and other visceral organs in adults. Am J Med 1979; 66: 457-462.

26. Nash G, Foley FD. Herpetic infection of the middle and lower respiratory tract. Am J Clin Pathol 1970; 54: 857-863.

27. Nicoll JAR, Love S, Burton PA, Berry PJ. Autopsy findings in two cases of neonatal herpes simplex virus infection: detection of virus by immunohistochemistry, in situ hybridization and the polymerase chain reaction. Histopathology 1994; 24: 257-264.

28. Oda Y, Okada Y, Katsuda S, Nakanishi I. Immunohistochemical study on the infection of herpes simplex virus, human cytomegalovirus, and Epstein-Barr virus in secondary diffuse interstitial pneumonia. Hum Pathol 1994; 25: $1057-1062$

29. von Lichtenberg F. Infectious disease. In: Cotran RS, Kumar V, Robbins SL, eds. Robbins Pathologic Basis of Disease. Philadephia, Saunders, 1989; pp. 318-320.

30. Steinberg KP, Mitchell DR, Maunder RJ, Milberg JA, Whitcomb ME, Hudson LD. Safety of bronchoalveolar lavage in patients with adult respiratory distress syndrome. Am Rev Respir Dis 1993;148: 556-561.

31. Baughman RP. Use of bronchoscopy in the diagnosis of infection in the immunocompromised host. Thorax 1994; 49: 3-7. 